\title{
Home Based Programs on Promoting Return to Work in The Phase II of Cardiac Rehabilitation After Coronary Artery Bypass Graft
}

\author{
Dewi Nur Fiana, Sunaryo B. Sastradimaja, Dian Marta Sari ${ }^{11}$
}

Departement of Physical Medicine and Rehabilitation, University of Padjadjaran/Hasan Sadikin National General, Bandung, Indonesia

\begin{abstract}
Background. The purpose of this case report is to present the benefit of additional home based intevention program given in cardiac rehabilitation phase II of a 50 year old male vetenarian post coronary artery bypass graft surgery.

Methods. A functional approach with the aim of maximising the potency of return to work was adopted. Home programs given in this patient is an additional prescribing of overground walking exercise alongside with supervised exercise with treadmill.

Results. Due to his role, he should handle 14 farm. His work required him to move arround in 500 meters each farm and he made significant progress from MET 3.2 to 6.29 within 6 weeks and able return to work 4 weeks after surgery.

Conclusion. This finding indicate that additional home based programs was an effective program to promote patient's return to work faster.
\end{abstract}

Keywords: $C A B G$, exercise, home program, return to work.

\section{Correspondence Detail:}

\section{Dewi Nur Fiana.}

Email: dewinurfiana@gmail.com

Department of Physical Medicine and Rehabilitation,

University of Padjadjaran/ Hasan Sadikin General Hospital Bandung, Indonesia 


\section{INTRODUCTION}

Coronary heart disease can cause premature disability, and hence socioeconomic problems. The prevalence of coronary artery disease in Indonesia in 2013 is $0.5 \%$ or an estimated 883,447 peoples. The number of patients with coronary artery disease highest in West Java Province as many as 160,812 peoples $(0.5 \%)$ and is also the leading cause of death. ${ }^{1}$ Coronary artery bypass graft $(\mathrm{CABG})$ is one of the intervention treatments of coronary artery disease by creating new channels through coronary arteries that are narrowed or blocked. CABG aims to overcome or reduce the inhibition of coronary artery flow due to the narrowing or blockage to the heart muscle.

Cardiac rehabilitation (CR) after $\mathrm{CABG}$ is a long term program that involves prescribed exercise, education, and counseling to limit physiological and psychological effects of cardiac disease and to enhance the psychosocial and vocational status of selected patients. CR starts in the hospital, before discharge, continues after discharge, in a supervised setting and transitions to a home based program to be continued indefinitely.

Cardiac rehabilitation is considered effective in reducing 1 to 3 year mortality by approximately $20 \%$. Cardiac rehabilitation aims to restore people with heart disease to health through a combination of exercise, education, and psychological support. However, with improving results regarding survival, more attention should now be paid to the postoperative quality of life, including the patients' ability to return to the workforce. The ability to return to the workforce must be regarded as a very important part of the postoperative outcome since many patients are still part of the workforce when they undergo cardiac surgery. ${ }^{3-5}$

In order for an exercise programme to be clinically useful, it needs to be practical, cost-effective and sustainable. Ideally, it should be simple enough for the patients to do at home and require no special equipment or skills. Traditionally centre-based cardiac rehabilitation programmes (e.g. based within a hospital, gymnasium or a sport centre setting) are offered to individuals after cardiac events, while homebased cardiac rehabilitation programmes have been introduced in an attempt to widen access and participation. Intervention review of home based programs and centre based programs supports the conclusions of both programs to be equally effective for improving the clinical and health-related quality of life outcomes in low risk patients after MI or revascularisation, or with heart failure.

\section{History}

A 50 years old patient had been suffering chest discomfort 2 years before his coronary artery bypass graft surgery. At first he ignored the symptoms because he still managed to do his work. He is a vetenarian,specialist in chicken farming. He has important role to check and maintain high quality of the mass chickens and 
eggs production. He responsible for 14 chicken farm own by the company where he work. His work requires him to walk for about 500 meters each farm and he visits 2-3 farms each day. $\mathrm{He}$ also need to stand, squat and bow while doing his job. He drove his car to reach every farm in different area.

The symptoms restrain him to do his work properly. He do not smoke but he is a passive smoker since almost of his working colleague are smokers. He did not seek further medical attention before because he was busy and thought that his symptoms were because of his condition as passive smokers. At that time, he also feel easily fatigue when walking more than 200 meters.

The chest dyscomfort worsened by time, mostly when he walk in slope upward street or when he walk in stairs. He had to regulary observe the chicken stalls and go around the farm. Walking in quite far distance, in uneven surface, go up stairs are something that he has to deal everyday. He worked 8 hours per day, 5 days a week. In the wekeend, he went to different city by driving his car alone for about $69 \mathrm{~km}$ from Cianjur to Bandung to meet his son. The patient got heart attack for the first time 5 month before his surgery. He did angiografi procedure and there were 3 obstructions on his heart vessels. He underwent selective coronary artery bypass graft based on his angiografi on october 2016. He got phase 1 cardiac rehabilitation during his 7-days hospitalization. He got discharge after able to walk independently.

\section{Baseline Evaluation}

Patient joined phase II cardiac rehabilitation one week after discharge. In first day, functional capacity and lower extremities strenght were assessed by measuring VO2 max with 6 minutes walking test and sit to stand test. Home program prescribe in the first day : overground walking exercise, 500-600 meters in 30 minutes.

\section{Outcome Measurement}

Based on the above initial evaluation, the following outcome measures were choosen. Depression Anxiety and Stress Scale (DASS) as a measure for psychological assessment. However, as the patient in this case report progressed it became necessary due to the urge return to work, the 6 minutes walking test and sit to stand test were used to assest functional capacity and lower extemities strenght. Following a standardized protocol of 6 minutes walking test, patient walked for 6 minutes after instructions to cover as much distance as possible. The distance completed after 6 minutes was recorded. Chair standing test, to assess lower extremity strength, both the patient's hand was placed on the chest, and sit on a seat height of $40 \mathrm{~cm}$ and they moved sitting down stand up during 30 seconds.

\section{Treatment}

Home based intervation program were added alongside with supervised exercise as the core of cardiac rehabilitation program phase 
II. Home program that added were overground walking, twice a week go in between supervised exercise, the intensity was the same as hospital based exercise, symptom limited, 30 minutes/ day. The additional home based program were reported 3 times/weeks while patient went to the rehabilitation centre for his cardiac rehabilitation phase II exercise training.

Supervised exercise were flexibility and cardiopulmonal endurance exercises. Flexibility exercise prescribing; frequency: 3 times/ weeks; intensity : hold for 10 second every movemet, 5 Repetition; type : stretching exercise for head, neck shoulder and ekstremities.

Cardiopulmonal endurance prescribing : frequency : $3 \mathrm{x} /$ weeks supervised; intensity : low to moderate $(40 \%-80 \%)$ of exercise capacity using HR reserve or karvonen method, achieved in first $6^{\text {th }}$ minute until $30^{\text {th }}$ minute, time : 5 minutes warm up - 20 minutes core exercise -5 minutes cooling down, type : aerobic exercise using static bike in first two exercise and continues with treadmill.

\section{RESULTS}

The patient showed improvement in physical function on the first two weeks of program, tested by Bruce exercise test. In fact, patient fitness classification were 6.39 METS (Fair fitness classification). Accordingly, patient return to work on the second weeks of rehabilitation program. As a result, he can go to the farm, but could not drive the car by himself due to not confidence. Patient finished phase II of cardiac rehabilitation in four weeks. The outcomes results show in table I.

\section{Table 1. Increasing of physical performance after rehabilitation program

\begin{tabular}{lll}
\hline \multicolumn{1}{c}{ Test } & \multicolumn{1}{c}{ Baseline } & After 4 Weeks Treatment \\
\hline 6MWT & 242 meters/ 3.2 METs & 606 meters/ 6.33 METs \\
\hline Sit To Stand Test & 5 times & 15 times \\
\hline
\end{tabular}

\section{DISCUSSION}

Physiological status after surgery were assessed to determine whether patient suffers post Intensive care syndromes. Critical illness and its treatment often result in long-term physical and neuropsychiatric morbidities that require high resource use during and after ICU period (1-4). Post ICU, patients often develop psychological disturbances or acute confusion, that has known as the post intensive care syndrome. Furthermore, there are cognitive impairment is reported in 30 to $70 \%$ of patients who survive after ICU period. ${ }^{8}$ In contrast, there was no deppresion, anxiety or stress in this patient.

The Rehabilitation Program in this case consist of exercises that has supervised by professional Physical Therapist. The program were flexibility exercise and cardiopulmonal endurance exercises, for 3 times per week, as long as four weeks. In USA, the frequency of supervised exercise is three times per week, for 8-12 weeks, and the duration was 45 minutes for each session. While in Canada, the same rehabilitation 
program is conducted for 6-8 weeks. Besides, in Europe, there is shorter duration and frequencies, that is 3-4 weeks for phase II. ${ }^{9}$

One of the important finding of this case report was increasing of lower limb strength and functional capacity of patient and he could gradually return to work in the second week of treatment. The increase in lower limb in this case is in line with Nahid et al., who examined the effect of cardiac rehabilitation in patients after coronary artery bypass surgery. The exercise has done by 3 times each week, for 4 weeks. The result was significantly increasing of lower limb muscle strength. ${ }^{7}$ According to the study on phase II cardiac rehabilitation in Indonesia conducted by Primasari (2014), that was 43 patients post coronary bypass, who underwent rehabilitation program for 4 weeks, and 11 session, compared their functional capacity with patients who did not undergo any exercise, and the result was the treatment patients has increased on functional capacity. $^{10}$

Home based intervention program were added alongside with supervised exercise as the core of cardiac rehabilitation program phase II. Home program that added were overground walking, twice a week go in between supervised exercise, the intensity was the same as hospital based exercise, symptom limited, 30 minutes/ day. Walking is usually the best-accepted form of exercise and is widely recommended for general health. ${ }^{6}$ Patient could return to work in the second weeks of cardiac rehabilitation phase II, shorter than usual duration of CR phase

\section{CONCLUSIONS}

This case reports the cardiac rehabilitation phase II of a patient post coronary artery bypass graft surgery with an aditional home based programs. There were improvement in lower limb strength and functional capacity and patient also could return to work in the second weeks of cardiac rehabilitation phase II, shorter than usual duration of CR phase II.

\section{REFERENCE}

1. Riset Kesehatan Dasar. Jakarta: Badan Penelitian Dan Pengembangan Kesehatan Departemen Kesehatan Republik Indonesia. 2013.

2. Pattanshetty RB, Borkar SS, Khetan SM. Effectiveness of low intensity exercises on six minute walk distance and haemodynamic variables in cabg and valve replacement patients during phase 1 cardiac rehabilitation in a tertiary care setup: a comparative study. Physiother res int. 2014;2:669-76.

3. Maznyczka A, Howard J, Banning A, Gershlick A. A propensity matched study of return to work outcomes after percutaneous coronary intervention and coronary artery bypass graft surgery. Heart. 2015;101(suppl 4):a64-a5.

4. Fonager K, Lundbye-Christensen S, Andreasen Jj, Futtrup M, Christensen Al, Ahmad K, et al. Work status and return to the workforce after coronary artery bypass grafting and/or heart valve surgery: a one-year-follow up study. Rehabilitation 
research and practice. 2014

5. Taylor Rs, Dalal H, Jolly K, Zawada A, Dean SG, Cowie A, et al. Home-based versus centre-based cardiac rehabilitation. The cochrane library. 2015.

6. Kosmadakis GC, John SG, Clapp EL, Viana JL, Smith AC, Bishop NC, et al. Benefits of regular walking exercise in advanced predialysis chronic kidney disease. Nephrology dialysis transplantation. 2012;27(3):9971004.

7. Nazari N, Hashemi-Javaheri A, RashidLamir A, Alaviniya E. Effect of cardiac rehabilitation on strength and balance in patients after coronary artery bypass graft. Medicine. 2014;

8. Hopkins RO, Suchyta MR, Farrer TJ,
Needham D. Improving post-intensive care unit neuropsychiatric outcomes: understanding cognitive effects of physical activity. American journal of respiratory and critical care medicine. 2012;186(12):12208.

9. Mampuya WM. Cardiac rehabilitation past, present and future: an overview. Cardiovascular diagnosis and therapy. 2012;2(1):38-49.

10. Ragawanti P. Effect of cardiac rehabilitation programs on functional capacity of post coronary revascularization patient using six minute walk-test. Folia medica indonesiana. 2014;50(2):86-91. 